\title{
A Learning Game For Youth Financial Literacy Education In The Teen Grid Of Second Life Three-Dimensional Virtual Environment
}

Chang Liu, Ohio University, USA

Teresa Franklin, Ohio University, USA

Roger Shelor, Ohio University, USA

Sertac Ozercan, Ohio University, USA

Jarrod Reuter, Ohio University, USA

En Ye, Ohio University, USA

Scott Moriarty, Thwakk, Inc., USA

\begin{abstract}
Game-like three-dimensional (3D) virtual worlds have become popular venues for youth to explore and interact with friends. To bring vital financial literacy education to them in places they frequent, a multi-disciplinary team of computer scientists, educators, and financial experts developed a youth-oriented financial literacy education game in the Teen Grid of Second Life 3D online virtual world. This paper presents the design and development process of this financial literacy education game, its learning effectiveness in classrooms, and lessons learned from the process.
\end{abstract}

Keywords: financial literacy; credit union; Second Life

\section{INTRODUCTION}

\section{Motivation}

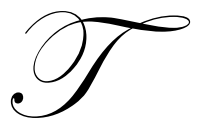

he financial conditions within the United States and the world deteriorated dramatically in 2008 and 2009. Disturbing financial news, declining stock portfolios, decimation of retirement accounts, record post-war unemployment projections, failure of iconic national companies, and unprecedented massive government spending packages to curtail the damage were frequent events in late 2008 and 2009 . Even before this financial crisis exploded, the U.S. consumer (the driving force behind the latest global economic expansion) was feeding this fire with record borrowings and virtually zero savings plans. In fact, as the chart below (Figure 1) highlights, personal savings actually dipped below zero in 2005.

These data highlight the continued need for financial education and are an indictment on past financial educational initiatives that have arguably left the majority of the U.S. population ill-prepared to manage one of the most critical aspects of their lives: their finances! 


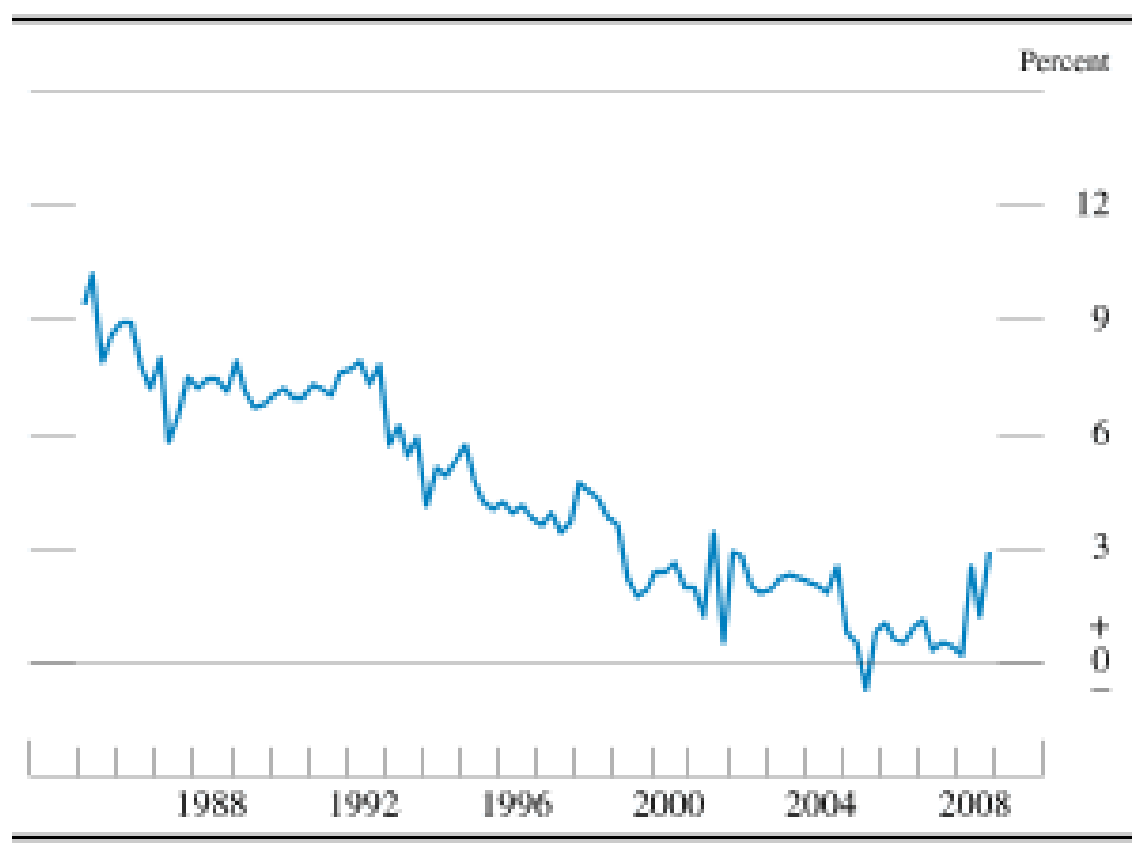

NoTE: The data are quarterly and extend through 2008:Q4.

Source: Department of Commerce, Bureau of Economic Analysis.

Figure 1. Personal Saving Rate, 1985-2008 [Board Of Governors Of The Federal Reserve System, 2009]

Listed below are some key statistics that highlight the need for action:

\section{Lack Of Assets:}

- $\quad$ Fully one quarter of the U.S. population is asset-poor. "A family is asset-poor is if it had to live only on their net worth -- savings, home equity and other assets -- they could survive at the poverty level for (only) three months." [Boshara, 2002]

- $\quad 46.8 \%$ of asset-poor families actually have zero or negative net worth [The New America Foundation, n.d.].

- 26 percent of white children, 52 percent of African-American children, and 54 percent of Hispanic children start life in households without any resources for investment [The New America Foundation, n.d.].

Debt:

- In 2005, household debt amounted to over $130 \%$ of disposable personal income [The New America Foundation, n.d.].

- $\quad$ There has been a $40.63 \%$ increase in home foreclosures from December 2007 to December 2008 [RealtyTrac Inc, n.d.].

- In 2005, nine out of every 1,000 adults declared bankruptcy [The New America Foundation, n.d.]. This is a number that will surely grow in the years ahead, despite legislation to make declaring Bankruptcy more difficult in 2005.

\section{Lack Of Financial Knowledge:}

- $\quad$ According to a 2007 survey by The Hartford Financial Services Group, Inc. the majority of college students say they learn more about personal finance from their parents, but less than half of Students say their parents make a consistent conscientious effort to teach them [Jump\$tart Coalition, 2007]. 
- $\quad$ This same study stated that students and parents agree that college students are not sufficiently prepared to deal with the financial challenges that lie ahead. Less than one-quarter of students (24\%) and only $20 \%$ of parents say students are very well prepared to deal with the financial challenges that await them after graduation [Jump\$tart Coalition, 2007].

- $\quad$ Further, this study stated that more than three-quarters of students (76\%) wish they had more help preparing for their financial future [Jump\$tart Coalition, 2007].

- $\quad$ According to a back-to-school survey by Capital One, $49 \%$ of teenagers are eager to learn about money management, but only $14 \%$ have taken a class on the topic [Capital One, 2009].

- $\quad$ According to survey of parents by Visa, $70 \%$ of parents surveyed said their child has not had any formal training in money management [Visa, 2005].

- $\quad 50-55 \%$ average score on financial awareness test by 12 th graders [Palmer, 2008].

If this has not highlighted the need for continued innovation for financial education, then perhaps the following statement may crystallize why relevant formats are needed for the younger generation. "For many Americans, talking about money is at least as uncomfortable as discussing sex. A recent Charles Schwab study found that most parents felt better prepared to give their teens advice on the 'birds and the bees' than on investing. That taboo may explain why Americans are so inept when it comes to making some of the most important decisions of their lives." [Palmer, 2008]

So if parents are ill-prepared to teach their children, the schools are not prepared to teach it, and current financial education formats are showing limited success in modifying behavior, then an immersive learning video game may be a good start!

Recent developments in computer graphics and networking technologies have made it feasible and economical to deploy realistic real-time 3D online virtual worlds accessible to average learners. Three-dimensional virtual worlds (3DVW) were highly appealing to the youth population. Could financial literacy education content be embedded in a 3DVW without decreasing the appeals of the 3DVW? In the past two years, the authors engaged in a project that attempted to do just that.

The project team started with a series of questions.

1. Is financial education a viable solution to prevent poor financial decision-making?

2. Are the current forms and delivery channels of financial education sufficient to inform future generations and prepare them for financial success?

3. Will financial education become a stronger focus of educators and legislators?

4. How can a computer learning game make a difference?

In this paper, 3D immersive learning environment as a potential future mainstream educational approach is highlighted as a possible solution for improving financial literacy of today's youth. There are reams of information and pertinent statistics associated with this crisis. As with any statistic, there are usually more pertinent details behind the data; however, one thing is indisputable: Everyone will all be forced to make critical financial decisions throughout our lifetime, and if one is not educated enough to make informed decisions, then he or she will continue to see an increase in the disturbing trends described above.

The goal of this project was to enhance financial education for the younger generations by creating an engaging 3D multiplayer game focused not only on providing information, but creating a safe format for players to actually take part in virtual financial transactions. This immersive format would expose them to various aspects of financial transactions they will be exposed to later in life, and more importantly, help modify their future behavior because they have experienced the event in the game.

This paper will explore the promising aspects of 3D virtual worlds as a viable educational tool and specifically highlight the early indications of potential for a financial education game [Wagner, 2007]. 


\section{Literature Review}

The appeal of state of the art technology for educational purposes has been studied and exploited in a number of applications. Throughout the years, as new entertainment technology became available, there have been efforts to use that media for educational purposes. One successful innovation was the adaptation of broadcast television by PBS for the Sesame Street educational programs, beginning in the late 1960's. Over the subsequent years, and in keeping with media technological advances, there have been creative applications of interactive instruction. These are attractive to students, educators and parents. Commonly referred to as edutainment, these applications meet the student where his interests lie, and may be more effective than other communication modes [Adams, 2006].

Currently, there is interest in expanding the participation of teens and young adults from online virtual social interaction to online educational activities. This can improve students' life skills while serving the interests of corporate or academic sponsors. Evidence of amusement oriented interactive game play transition to edutainment may be found in Second Life university course offerings. An example of a recent Second Life business continuing education application is the CPA Island, sponsored by the Maryland Association of Certified Public Accountants (MACPA). Visitors have the opportunity to interact with others while participating in seminars and self-guided continuing education. This provides young professionals with an exciting format for learning about accounting matters [Johnson, Middleton, 2008].

Another business education opportunity in Second Life is presented by Wood, et al. [Wood, Solomon, Allan, 2008], who address advances and changes in marketing and sales training delivery modes. They discuss the increasing preference for online instructional delivery. Convenience, quality and appeal to young users are all enhanced by online delivery. Advances in the areas of distance learning are discussed by Wood, et al. [Wood, Solomon, Allan, 2008] and by Johnson [Johnson, Middleton, 2008] and Allen and Seaman [Allen, Seaman, 2006], who describe the transition of distance learning from correspondence courses to methods of delivery that incorporate videoconferences, email and websites that are specific to individual courses. Teens are more attracted to computer based instruction because of their heavy exposure to a variety of internet activities, such as YouTube, email, IM, and relationship websites such as MySpace and Facebook. Online learning activities are a natural extension of the media with which they are comfortable.

A discussion of purposeful and general purpose virtual worlds is presented by Wagner [Wagner, 2008]. Purposeful configurations are those virtual environments wherein participants have increasingly complex and difficult requirements. Although these activities may be learned in a virtual world, planning and organizational skill are needed for real life success and virtual lessons learned can be applied in real world scenarios. General Purpose environments lend themselves well to classroom instructions because the game contains its own set of rules and objectives and the instructor does not have to design these for each application or lesson.

\section{Context}

\section{Marketing}

A challenge for credit unions is to inform potential customers about the benefits of choosing a credit union as their provider of banking services. Credit unions have several competitive advantages over commercial banks and savings and loan organizations.

Depository institutions commonly referred to as banks provide basic financial services to individuals and businesses. Depository Institutions are organized and owned in a variety of ways. Some operate nationwide and internationally; among the largest are JP Morgan Chase, Wells Fargo, the Royal Bank of Canada and the Bank of New York. These have a national charter and are owned by shareholders. Regional banks typically serve customers in one or two states and are also typically owned by shareholders. Community banks may be smaller and usually operate within a single state. These may be owned by shareholders or may be privately held. Savings and Loan organizations are owned by their depositors. Credit unions are nonprofit, owned by members who must have some 
affiliation, such as place of employment or an organization. Credit unions are associated with, but independent of, the employer or organization.

All of these types of depository institutions are similar in function, yet differ in charter and federal and state regulatory agency. All types offer basic financial services such as checking and savings accounts, certificates of deposit; debit and credit cards; and automotive, real estate and other loans. Since the implementation of the GrammLeach-Bliley act in 1999, many depository institutions also offer insurance products and investment services.

Credit unions and Savings and Loan associations are nonprofit and owned by account holders or members. As such, there is no expectation of dividend payment to shareholders and less revenue is needed because there is no profit expectation. In addition, credit unions are exempt from Federal Income tax liability. The combination of taxexempt status and lack of need to pay dividends enables credit unions to offer loans at lower rates and to pay higher returns for deposits. These are distinct competitive advantages for credit unions. The financial products offered by a credit union are similar to those offered by other depository institutions, but the fees for deposits and loans are typically better than those among Community Banks operating in the same markets.

Informing potential customers of these benefits of credit union membership is a long standing challenge. Aside from routine advertising at the local level, word of mouth is another means for promoting credit union membership. The Financial Literacy game provides an innovative method for educating teens and young adults about the benefits and services offered by credit unions while increasing their financial responsibility awareness.

\section{Risk Reduction}

Depository Institutions are exposed to a variety of risks. Default risk relates to customers who borrow more than they can afford. When a customer applies for a loan to purchase a home or car, a credit report score gives the lender an indication of the customer's ability to repay. A better (higher) credit score reflects less default risk exposure and means that the borrower is more likely to have the loan approved, and at a lower interest rate.

Teens and young adults may not understand that their spending choices affect their credit score and their ability to save more for retirement or other objectives. The value of the Financial Literacy Game is that it provides training for teens and young adults about matters pertaining to wise spending choices and personal responsibility. Students learn about earning, budgeting, credit management, and accumulating savings and building equity in a home.

The Financial Literacy Game players become familiar with the process of applying for and obtaining a car loan or home mortgage. The factors that are included in both the loan application process and the approval decision are introduced in the game.

Young adults who know more about financial products will become better customers and will be less likely to overextend themselves in debt. These customers should be less likely to default on loans [Stone, 2004]. Both the lender and the borrower will be well served by this result.

\section{BACKGROUND}

\section{Second Life And 3-D Virtual Environments}

Second Life (SL) [Rymaszewski, Au, Wallace, et al., 2007] is arguably the most popular 3-D Online Virtual World with more than 10 million registered accounts. A Virtual World, also known as Synthetic World [Castronova, 2005], is a computer-simulated persistent environment similar to the real world. It is usually created for its users (also known as residents) to inhabit and interact through avatars. An avatar is the user's representation in the virtual world. Like many other virtual worlds, SL can support a massive number of players online at the same time. Thus it is also called a massively multiplayer online virtual world. 
SL includes various communication methods including text chat, Instant Message (IM), and voice chat. Chat is usually used to talk with other residents locally in a public fashion, and all the residents nearby within a certain distance can hear it. IM is used for private conversation among two or more people. Other people cannot hear it even they are nearby. SL supports voice chat through Voice over Internet Protocol (VoIP). SL provides various gestures and animations to enrich the communication.

SL has a wide spectrum of online activities, including arts, science, sports, and education. Within it, the residents can explore, meet other residents, socialize, and participate in all kinds of activities. For example, you could attend a performance played by famous musicians, and it could be free and available when you are available without travel.

SL offers powerful creation tools including a 3-D modeling tool, and a script language called Linden Script Language (LSL). LSL is an event-oriented language, and its syntax is similar to C. The 3-D modeling tool is used to create objects in SL, while LSL is used to add logic to the objects and control the objects' behaviors. Most of the content in SL is actually created by its users using these creation tools. And the users own the intellectual property of their creations.

SL has made its client software open source, and plan to open-source its server software in the future. SL supports in-world (i.e. inside SL) and out-world (i.e. outside SL) interaction mechanism by using XML-RPC and HTTPRequest. By using these open and extensible features, residents have developed various tools bridging SL and real life. For instance, Sloodle is a virtual environment learning system that integrates SL and the Moodle learningmanagement system [Kemp, Livingstone, 2006].

\section{Current Financial Literacy Education Situation}

Many teens and young adults obtain their understanding about personal finance from observing their parents' spending behavior. A child may notice a parent making purchases in grocery or department stores using debit or credit cards. The child might not understand the association between the purchase and the funds that are behind the expenditure. When teens and young adults first make independent choices about financial matters and spending patterns, they may have an unrealistic perception of what they can afford. In an attempt to maintain the same level of consumption as their parents they quickly accumulate credit card and student loan debt.

There are other financial literacy issues that are confusing but important for young adults. Establishing and maintaining a satisfactory credit score affects a variety of areas such as eligibility for consumer credit, a home mortgage and automotive insurance rates.

It is not uncommon for a graduate of a state university to gradate with $\$ 60,000$ in student loan debt and several thousand dollars of credit card debt. Furthermore, graduates of professional programs, such as law school or graduate school often accumulate $\$ 100,000$ or more in student loan debt. Most American graduate students have 6 or more credit cards and for a significant number of these, the total debt of these cards is greater than $\$ 15,000$ [Kantrowitz, 2010] [American Medical Association, n.d.] [Dugas, 2009].

Teens may make most of their purchases with cash, debit cards or gift cards. They may not realize that to purchase a large ticket item, such as a car, it is often necessary to borrow most of the money. The complexities of making a proper choice and applying for a loan can be overwhelming. This is in contrast to the ease with which college students can obtain credit cards.

\section{RELATED WORK}

A number of learning games have been developed in Second Life and other similar virtual worlds.

\section{Appalachian Tycoon}

Ye et al. from Ohio University have developed an environmental education game for high school students, Appalachian Tycoon, in SL [Ye, Fang, Liu, et al., 2007]. It aims to let students increase environmental awareness through a fun game. 
The game is designed to specifically simulate stream pollution. It is a single-player game in which the player serves as the user of the stream bank, which is initially grassland. Initially, the player is given 1000 points (representing money) and 200 time units. In the game, the player can spend money developing the stream bank by choosing one of the following options: surface mining, power plant, commercial farm, organic farm, residential land, and planting trees. The goal of the player is to maximize both economic and environmental benefits from his or her investment, i.e. to gain a score as high as possible, in the limited time. As the game proceeds, the player will stay informed concerning how many points he or she has gained or lost and why. To obtain a good result in the game, the player has to know the effects every land use option contributes to the environment. These effects are portrayed in the game as they occur. The player learns about environmental issues unconsciously while playing the game. A screenshot of Appalachian Tycoon in action is shown in Figure 2. The game has been tested among students from Athens High School and Meigs High School, and earned promising results from survey answers.

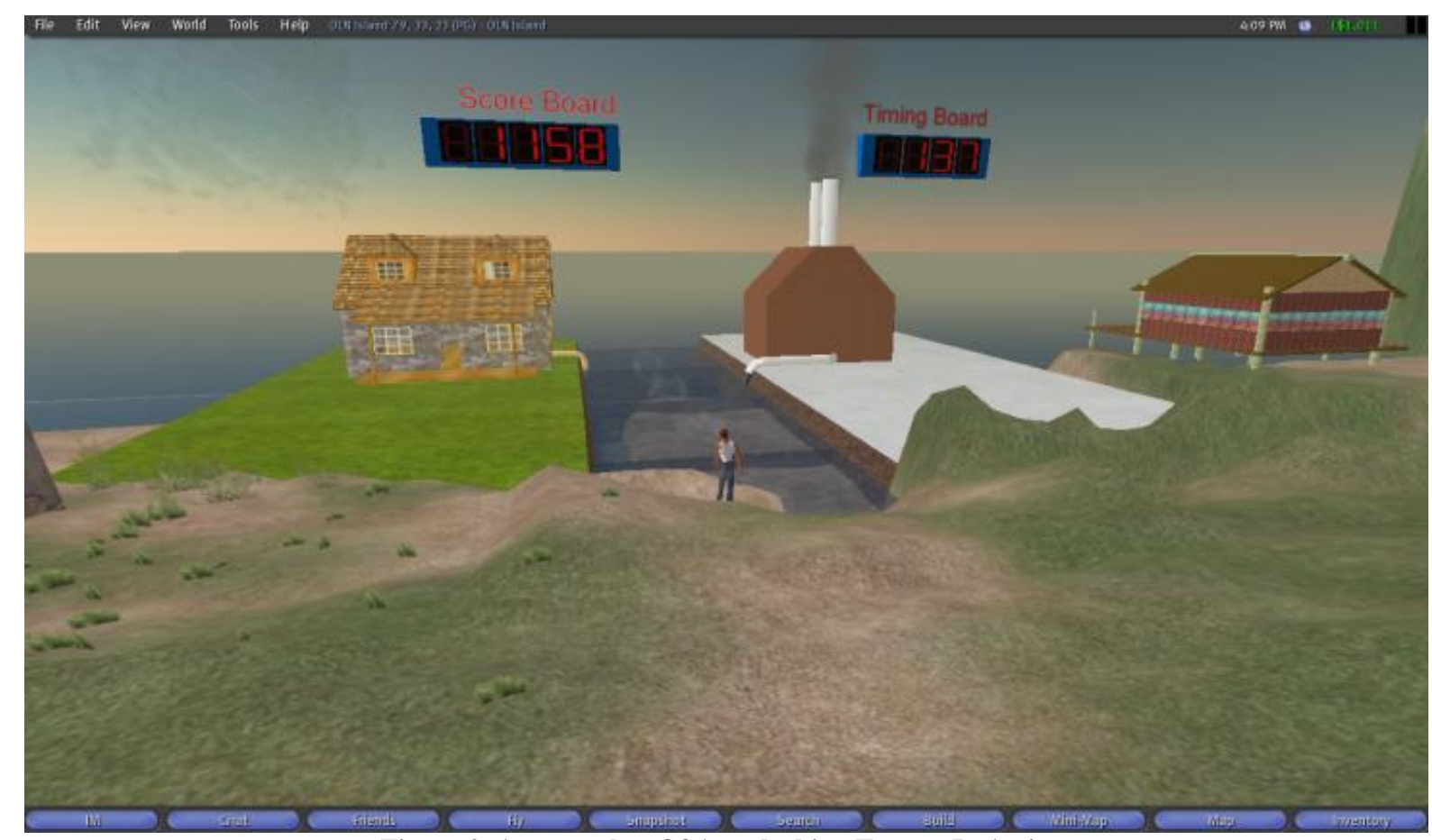

Figure 2. A screenshot Of Appalachian Tycoon In Action

\section{Virtual P3 ${ }^{\text {ii }}$}

Fang et al. have designed and developed a computer game named Virtual P3 in which the players could learn the knowledge of chemical exposures in daily life while they are having fun [Fang, Siemer, Zhong, et al., 2008]. It is a computer-simulated 3-D game that aims to improve public awareness of chemical pollutants in their daily life and of the alternatives to protect their health. It uses the form similar to Monopoly Game, the best-selling commercial board game in the world, and game rules are similar to the original. However, instead of the economicprofit-centered theme in the traditional game, Virtual P3 advocates 'environmental profits', which represent the positive impacts on the environment. Players try to earn as much 'eco money' as possible by taking various environmentally conscientious actions. The game is developed on OpenSimulator ${ }^{\text {iii }}$, an open-source 3D Application Server, which is similar to Second Life server. Since it is open-source, schools can set up their own server, and have the full control of the content. A screenshot of Virtual P3 is shown in Figure 3. In April 2008, Virtual P3 won an honorable mention in the 2008 U.S. EPA P3 (People, Prosperity, and the Planet) competition in Washington, D.C. At the competition Expo, the game not only received highly positive comments from the judge panel, but drew a large group of children as well as adults, including teachers from elementary schools and middle schools. 


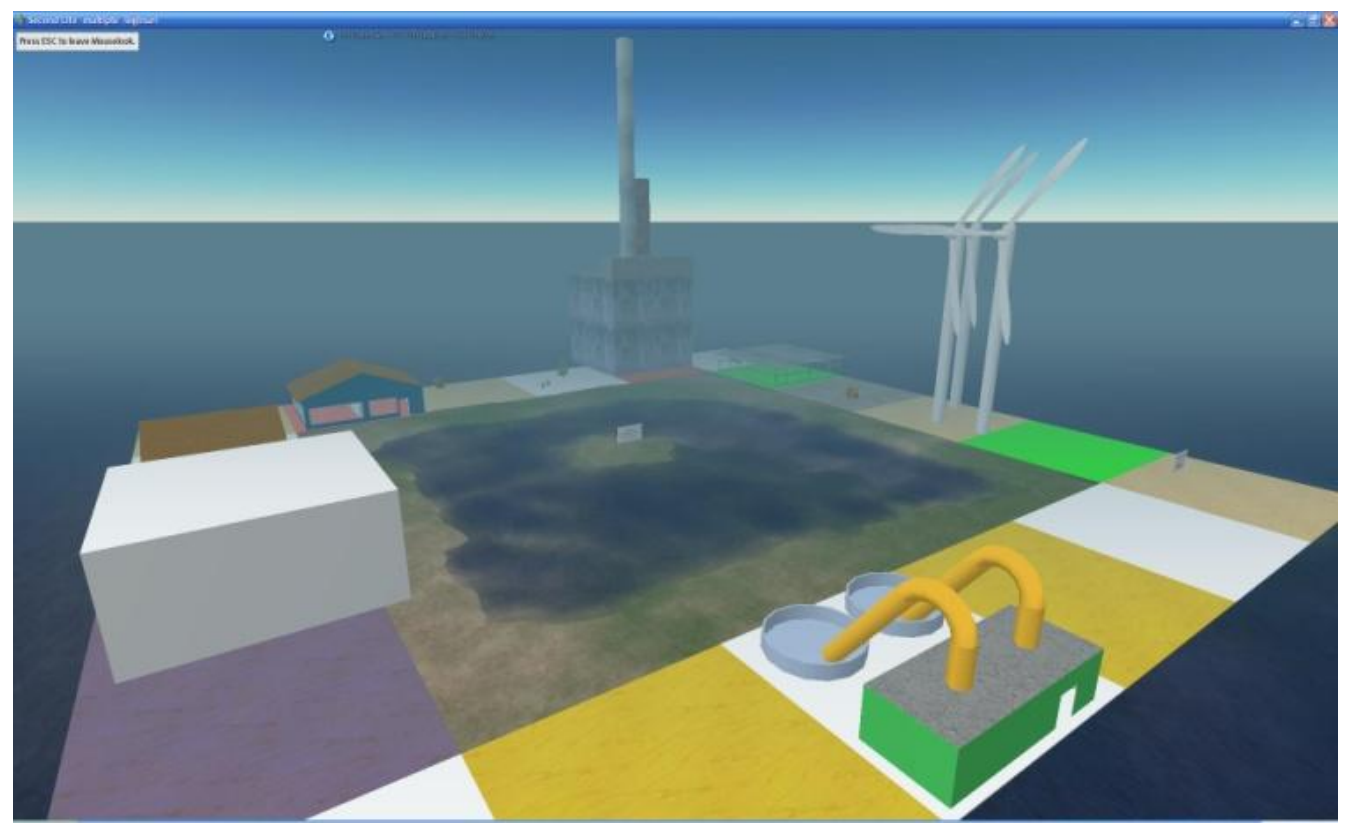

Figure 3. A Screenshot Of Virtual P3

\section{Two Software Engineering Educational Games In SI}

To enhance software engineering education, En et al. have developed two 3-D multiplayer online software engineering educational games in SL: the SL Groupthink game, and the Role Play Game for Software Engineers (RPG-SE) game [Ye, Liu, Polack-Wahl, 2007]. They have been applied in two computer science classes, one at Ohio University, the other at the University of Mary Washington. By playing them, students learn fundamentals of software specification activities and principles of software development processes. According to the data collected from student surveys, most of the students indicated the two games are helpful.

\section{FINANCIAL CONCEPTS COVERED IN THE GAME}

The goal of promoting financial literacy among teens and young adults is challenging because most of these people have little experience with money matters. It is easy to overwhelm and confuse students because the expenses related to establishing and maintaining an independent lifestyle issues are so complex. As teens enter the adult world, they are immediately bombarded with opportunities to go into debt, in the form of credit cards, store issued credit cards and auto loans. The process of obtaining a home loan can be overwhelming, even for someone who has years of life experience. Many college graduates have overwhelming student loan debt.

In light of this, a priority of subjects that are included in financial literacy training was established. The first objective is for the player to understand that there are high costs associated with purchasing a car, buying a home and everyday living expenses. There are several topics that are essential for the development of financial literacy. The area of Money Management includes training about budgets and developing an understanding about Credit Scores and the effect these have on other financial matters. Financial Planning includes development of financial goals, planning for retirement, and good recordkeeping. Basic Investing covers the fundamentals of checking and savings accounts, certificates of deposit, investing in mutual funds or stocks and bonds. Also in this area is a discussion of the tax shelters and other advantages that are associated with IRAs, 401(k) and 403 (b) plans. Insurance matters cover the importance of Auto, Homeowners and Renters Insurance, Life and Health and LongTerm Care coverage. Residence training covers the rent or buy - an Apartment or a House - decision and the advantages and disadvantages of these and the process of selling a home and moving. Career choices address the decision to attend college or seek employment, deciding on a major and whether to seek part time employment while in school. 


\section{GAME DESIGN}

\section{Game Play}

Financial Literacy Game is a role-playing game, which can be played with either multiple players or a single player. A player starts the game as an 18-year-old just graduated from high school. The player would face a number of decisions as the game progresses, such as whether to go to college or find a job right away; what kind of career to pursue; what kind of car to buy or to lease; when to rent an apartment; when to move to a house; what kind of house to buy or lease; whether and when to invest in retirement accounts etc. Shown in Figure 4 is the overall game design diagram, illustrating different paths that players can take. Based on player decisions, the financial condition of the player will be updated once every few seconds, which are equivalent to two weeks in the simulated player life. If a player does not manage his or her finance well, there is a chance that he or she may go bankrupt before the retirement age of 65 . If the player manages to reach retirement age in the game, the wealth he or she has at retirement will be a key factor in his or her final game score.

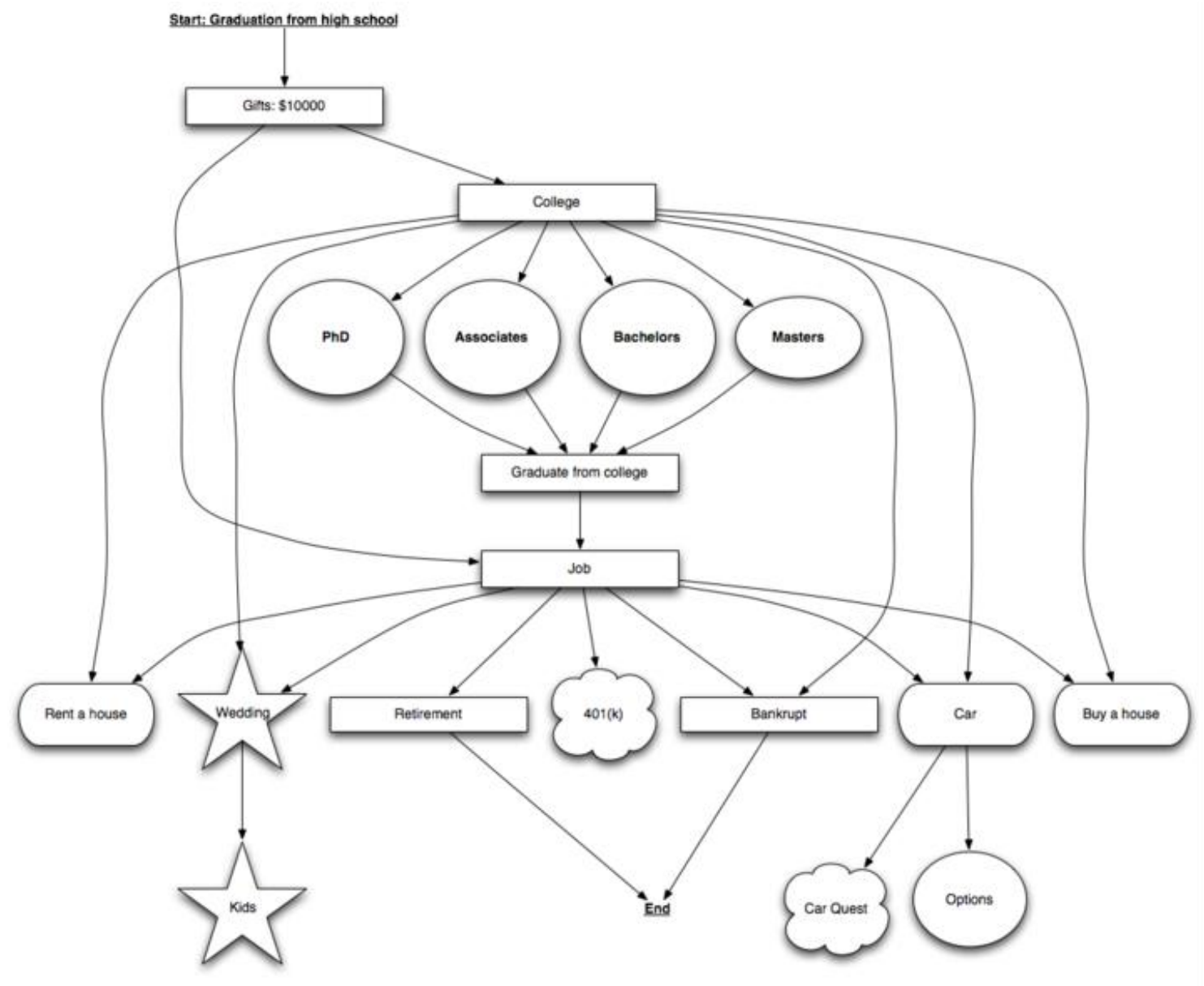

Figure 4. Overall Game Design Diagram

A key aspect of the game is that players are expected to fail multiple times before they complete the game successfully. As they learn how to reach a satisfactory retirement in the game, they are forced to learn basic financial concepts and disciplines because that is the only way to stay in the game without early bankruptcy. 


\section{Quests}

In the process of the game, players must complete a list of questions that test their knowledge of different financial situations. Shown in Figure 5, these questions are presented when players make major life decision such as buying a car or house. Before the questions are asked, players may choose to view a video that presents information on the given quest. The quests are meant to inform the players about what information needs to be known when purchasing certain life items.

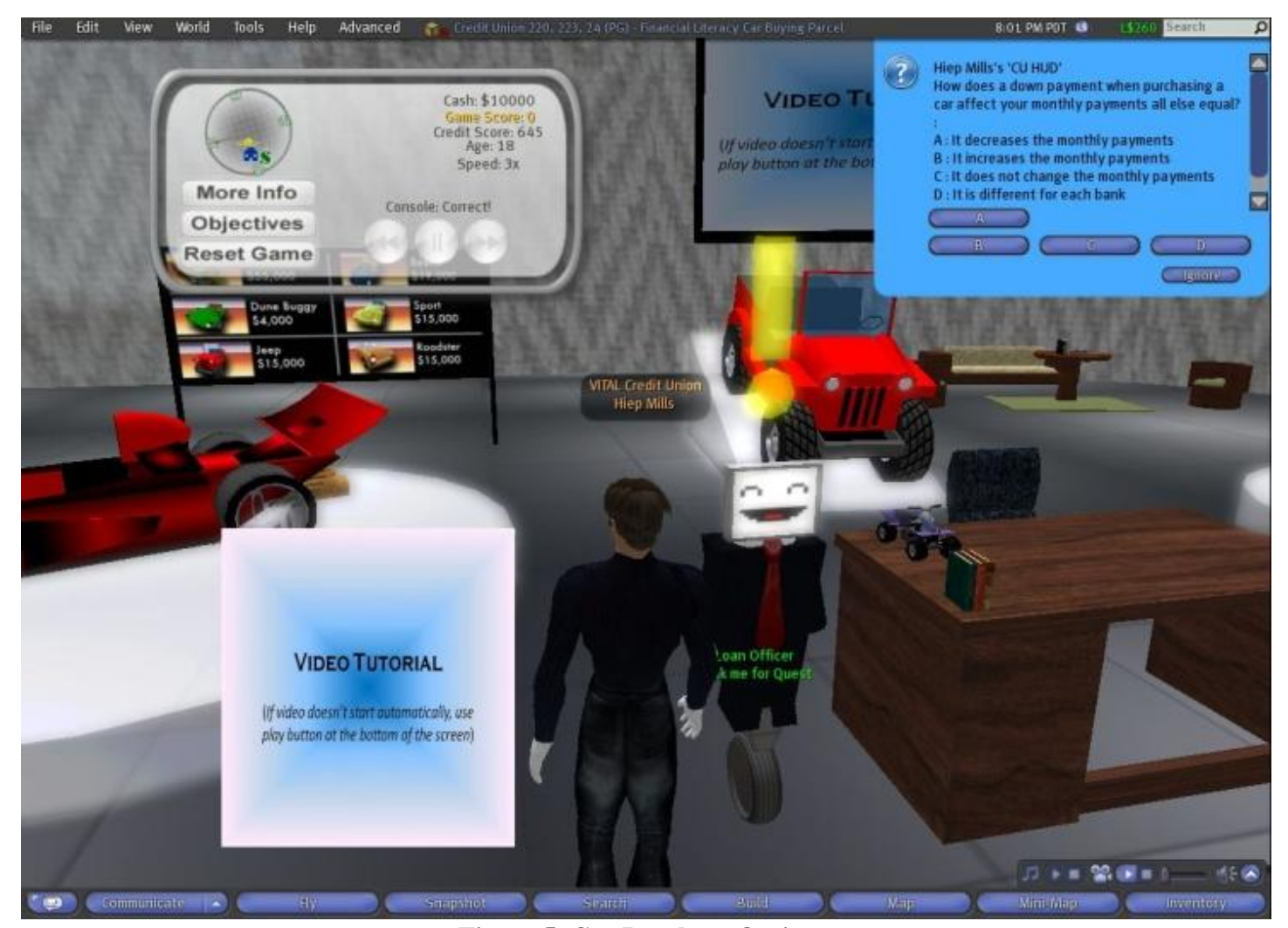

Figure 5. Car Purchase Options

In each quest, when the player navigates through the game and obtains a scenario where a purchase is possible, a screen is displayed. For example, when the player goes to the car dealership there is a screen on the wall that the player can touch where a video is presented. The car quest has a video of a person at a car dealership speaking with a car dealer. This shows a typical situation that a person may go through when trying to purchase a car. It allows the player listen to information that is imperative to know when making such major life decisions.

There are a number of quests currently in the game. Some quests topics include: how to purchase/finance a car, the decision to buy or rent a house, and how to finance a house. After the student views the video, approximately four multiple choice question will be asked that test an array of the player's knowledge on that particular topic (Figure 6). Unbeknown to the player, the more questions that are answered correctly the better deals they will receive from the dealer (Figure 7).

There are many directions that the quest could have gone. In order not to lose a typical player's (high school students) attention, the quests were limited to basic information about each topic. These quests can be as in depth and informative as the real life situations. As the game evolves, future quests will be put into the game that covers more topics. 


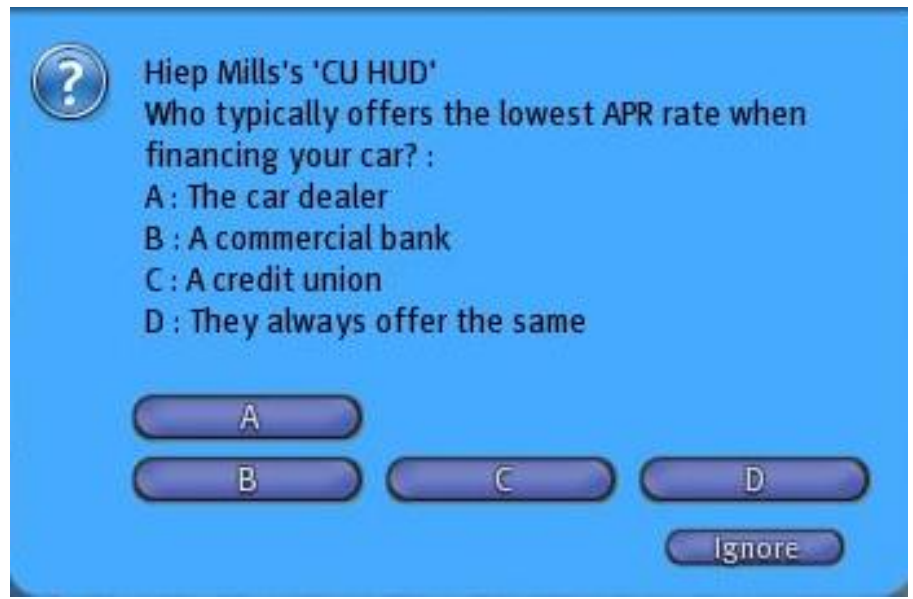

Figure 6. Sample Car Quest Question

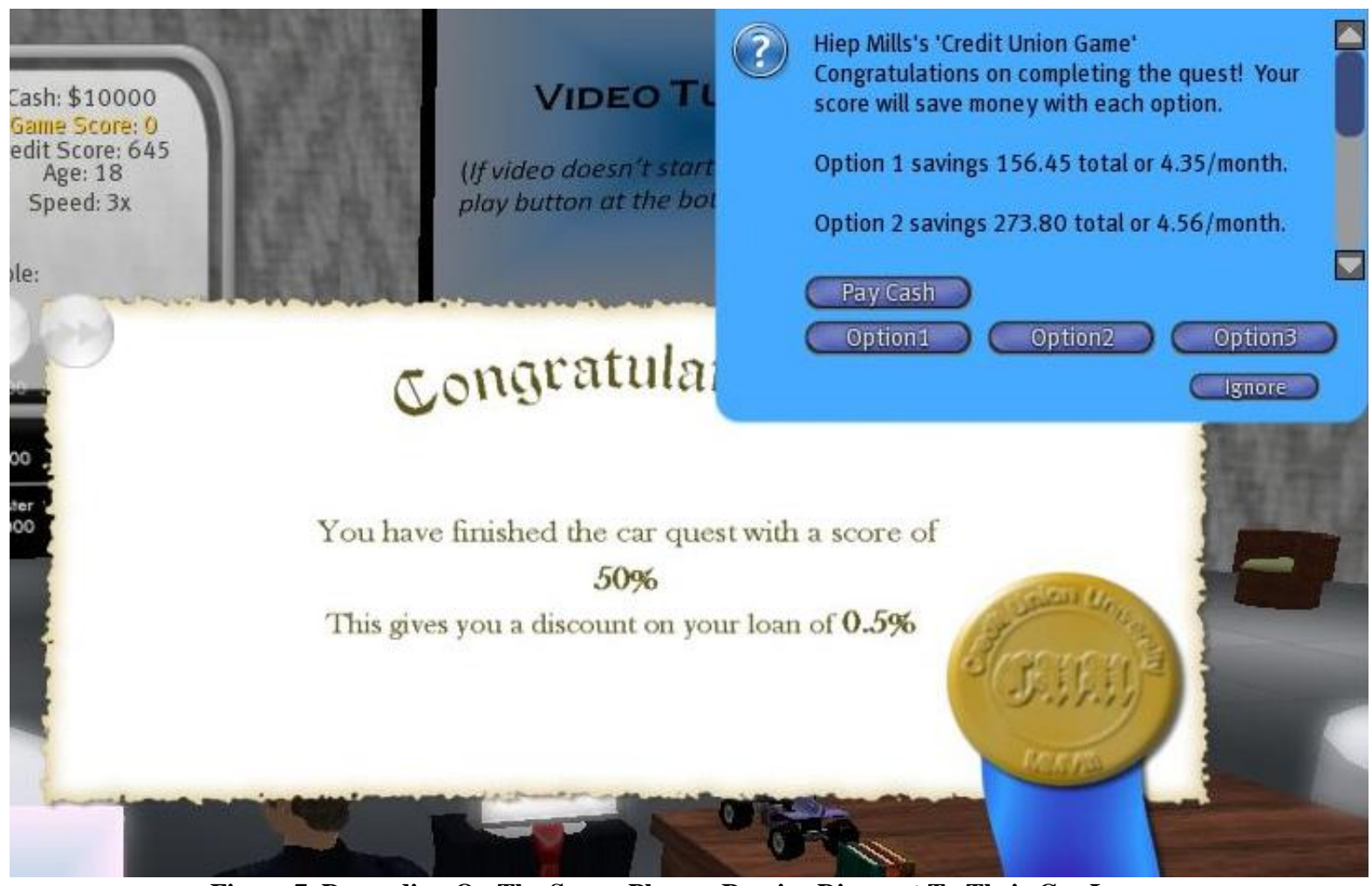

Figure 7. Depending On The Score, Players Receive Discount To Their Car Loans

Every time a player goes through the game they will be asked questions on the certain topics. The more times the player goes through the game the more in-depth the questions become. The quests are meant to inform the players and make sure that the game is 'value-added' to their education.

\section{Architecture}

Second Life provides a scripting language called Linden Scripting Language (LSL). LSL is an event-driven scripting language, which is used internally by Second Life. LSL allows controlling behavior of objects and avatars. 
It offers over 300 built-in functions, and more can be created by players. LSL scripts need to be attached to objects in order to modify their behavior. Once scripts are written by players, they are saved to Linden Labs servers, compiled into bytecode and interpreted by Linden Labs servers. Each script receives a limited memory space for its bytecode, heap and stack.

Communication of objects in SL is similar to radio communication. The scripts attached to objects communicate with the use of chat channels, similar to radio frequencies. Communication between objects occurs when an object broadcasts a message to a chat channel, while other objects listen to the same channel. While players can use any chat channel number, they can only see chat messages in channel 0 , however, objects can communicate with any integer number.

There are several aspects that need mentioned in regards to the game's architecture. The main portion of the game is in a HUD, which can be purchased on the island and will auto attach to the avatar. There are items throughout the island that are scripted to provide interaction during game play. Some of these items include vehicles at the car dealership, 'For Sale' signs in the housing development and a loan officer at the dealership. When these items are clicked they send a message to the entire island of which avatar is interacting with the item. These coded messages are read by the HUD, parsed for data and then sent to multiple scripts within the HUD. The use of multiple scripts in the HUD is largely due to space limitations for an individual script in Second Life. The scripts are divided into logical tasks. These include: listening for dialog messages, timed game events, credit score, car details, home details, quest interaction, and navigation just to name a few. At times, scripts need information stored in others to complete their tasks. An example might be when someone buys a car. The car script needs to first see if the player has a car to determine if the player has a trade in amount from the dealership. It then sends a message to the credit script to obtain the player's credit rating. The credit script will check with the home script and others (cash, age, etc) to determine what the credit score should be. Once the credit score is calculated and sent back to the car script, purchasing a car can commence. All of this complexity needs to be efficient or the person playing the game will notice a lag. One way to help with this efficiency was to spread out the scripts into multiple objects in the HUD. This allows scripts to send messages only to a certain object and the others do not need to parse and interpret this data. However, scripts that share data regularly were kept in the same object, allowing only one message to be sent to that object and interpreted by all those scripts.

\section{INITIAL RESULTS}

Usability beta testing within high school students ranging in age from 15 to 18 was completed on February 6, 2009, with the following results found in Table 1. The Financial Literacy Game Usability Survey is attached. Item analysis on the scale was satisfactory with only minor changes in the structure of the questions from the pilot and the scale maintained a Cronbach Alpha of .69. In Part 1, a five point Likert Scale with $5=$ 'strongly agree', $4=$ 'agree', 3 = 'neutral', 2 = 'disagree' and 1 = 'strongly disagree' was used to code the outcomes of student reflections on the usability of the Financial Literacy Game. Reverse coding was used with negatively stated questions to maintain the integrity of the scale.

It is interesting to note that lowest value on the Likert scale occurred in question 15, 'I think the game is a waste of time for learning finance'. The value of 2.30, which fell within the 'disagree' range suggests that students find the game a useful endeavor. Question 20 garnered a high value of 3.55 (close to $4=$ agree) in which the students indicated that 'The words were easy to read'. This is an interesting value considering the fact that often students do not read the content of the game or complain that the reading level is high or they lack understanding of terms. Question 5 had the highest value on the usability scale for game structure with a 3.63 (close to $4=$ agree), which stated, 'I had difficulty in navigating the game'. This score along with student comments suggests to the game designers that some changes need to be made in the navigation from one section of the island to another so that avatars can move through the environment in a more understandable fashion. 
Table 1: Part 1: Mean Scores For Usability Testing Indicating Agreement With Game Structure $(\mathbf{N}=\mathbf{5 4})$

\begin{tabular}{|c|c|}
\hline Question Number & Likert Scale Value \\
\hline Q1 & 3.43 \\
\hline Q2 & 3.17 \\
\hline Q3 & 3.52 \\
\hline Q4 & 3.17 \\
\hline Q5 & 3.63 \\
\hline Q6 & 3.08 \\
\hline Q7 & 2.56 \\
\hline Q8 & 3.17 \\
\hline Q9 & 3.51 \\
\hline Q10 & 2.30 \\
\hline Q11 & 3.08 \\
\hline Q12 & 2.56 \\
\hline Q13 & 3.17 \\
\hline Q14 & 3.51 \\
\hline Q15 & 2.30 \\
\hline Q16 & 3.57 \\
\hline Q17 & 2.74 \\
\hline Q18 & 3.17 \\
\hline Q19 & 2.85 \\
\hline Q20 & 3.55 \\
\hline Q21 & 2.56 \\
\hline
\end{tabular}

In Part 2, a Likert scale of 1 to 5 was also used with the Satisfaction Level of Game Play (5 = 'strongly agree', 4 = 'agree', 3 = 'neutral', 2 = 'disagree' and 1 = 'strongly disagree'). The satisfaction level with game play produced higher mean scores than the usability scores for game play. Satisfaction Question 5, 'How satisfied are you with this new way of learning?' provided a score of 4.0 (agree) which was the highest score obtained in the beta testing. In the Satisfaction Level for Game Play, all scores were in the 'agree' category ranging from 3.30 to 4.0 which suggests that students were in agreement that this form of game play improved their financial skill and provided enjoyment in learning about finance.

Table 1: Part 2: Mean Scores For Usability Testing Indicating Satisfaction Level Of Game Play (N=54)

\begin{tabular}{|c|c|c|c|c|}
\hline S1 & S2 & S3 & S4 & S5 \\
\hline 3.36 & 3.38 & 3.30 & 3.52 & 4.0 \\
\hline
\end{tabular}

\section{DISCUSSIONS AND LESSONS LEARNED}

\section{Technology}

Designing a game in Second Life that mimics real life in many ways presents numerous difficulties. The most restrictive difficulty faced from a programmer's perspective is the limitations of the LSL2 scripting language used on the Second Life server. This language was designed to give novice users the ability to write useful scripts. While it serves its intended purpose, little thought seems to have been given in the area of expansion. The language does not support Object Oriented programming or dynamic memory allocation. When these issues are combined with a limited $16 \mathrm{~KB}$ stack, creating the logic to include the complex calculations and multitude of options used to mimic real life financial situations becomes quite difficult.

When the game was first being developed, the logic was still fairly simple and the 16KB stack was not yet posing a problem. As the game became more complicated and more features began being added, the limitations started to restrict the implementation of new features. To overcome these limitations, a number of solutions were developed. 
To ease the pressure on the $16 \mathrm{~KB}$ stack, linked messages were used to communicate between scripts and limited each script to only a small number of variables. Each script listens for their messages in a comma-separated format. The script breaks these messages into pieces and treats one part as a function call and the remaining parts as data to act on in that function. Since each real function call carries overhead, each function created had to be compared to the memory used if the code was kept inline. Because of this comparison if a function was used in only a few places and relatively small in complexity it was more efficient to keep the code inline. All of these items combine to make a complicated architecture to the code, which impedes bug fixing and new feature implementations.

More recently, Second Life has added the Mono scripting-engine to the system. With this addition, scripts are given a $64 \mathrm{~KB}$ stack and dynamic memory allocation. These advantages have given the game's scripts more space and alleviated many of the memory issues. The games has been has been forced to maintain the architecture as the source code is in the LSL format, disallowing Object Oriented programming. Since Mono supports other languages, the hope is that Second Life will eventually support other languages for scripting. If this occurs, the scripts can be restructured to include Object Oriented code, pointers, and includes. These features will make expanding, reusing, and maintaining the code more manageable.

It was useful to begin with as many scripts as possible. Although this sounds counterproductive, when the project expanded, it made programming in LSL2 much simpler. The alternative is to separate the code when needed, which could introduce more bugs and become a tedious task.

It would be good to separate the code, and build the structure for storing and communicating between scripts first. This provides a base of how much memory a script is using just to communicate, and while beginning to make a project inside this structure. Programmers should continue to check the allocated memory for the script and continue to evaluate what data needs stored in each script.

Avoid the list type in LSL if possible. This data structure is useful, but uses space for the variables and to store what type each variable is. When developing a large project this memory use overshadows any advantage in readability that can be gained by the list type.

\section{Multidisciplinary Development Team}

Developing a 3-D computer game for learning requires expertise from the following types of specialists:

- $\quad$ Computer scientists, for game coding and scripting;

- $\quad$ Education experts, for evaluating and improving learning effectiveness;

- $\quad$ Domain experts, for selecting and refining content;

- $\quad$ Art designers, for developing 3-D structures and producing machinimas;

- $\quad$ Project managers, for project management.

A multi-disciplinary team of faculty and students from Computer Science, Educational Studies, Finance, and Communication, including a Computer Science faculty member, a Computer Science Ph.D. student, two Computer Science Master's students, an Educational Studies faculty member, an Educational Studies Ph.D. student, a Finance faculty member, an MBA student, a project manager, an art designer, a film student, and two art design students, was assembled to achieve project goals. In addition, a team of executives from the credit union industry worked with the project team to share their vision and insights. In particular, one of them worked closely with the Ohio University project team and functioned as a team member. The Ohio University project team worked with teachers and students in the region to beta-test the game during development and received valuable feedback.

The multidisciplinary nature of the project team and the convenient access to industrial expertise was an important factor that helped make the project a success. 


\section{FUTURE WORK}

As development continues on the next phases of the game, a discussion of future work and ideas is warranted. The potential scope of the overall game is tremendous. This article sought to break the scope into bitesize pieces where possible. One way to organize the discussion is to use the financial life stages that individuals may go through.

For example:

Childhood: Can be implemented as a tutorial stage where goal is to establish the basic game play mechanics for the rest of the game. The goal is to cover basics of savings, budget, interest rates, deposits, withdrawals, chores, and allowance.

College: Planned for phase 2 of the game, players will be able to choose from multiple college majors, which will have their own durations, fail rates and activities. In addition to this, the game can expand to have student loan choices, borrow from mom and dad, budget to pay bills (electric, gas, etc), credit card offers, tough choices (concert, road trip, etc).

Career: Planned for phase 2 of the game, players will be able to choose from multiple career choices with salaries, promotions, and activities.

Home Ownership: Currently, the game includes different loan types (1st mortgage, 2nd, etc), housing choices (buy and fix, buy and live, etc), and housing upgrades that can add value (home equity), market conditions that can improve or devalue your home. Future things to consider could be crime rate, living within means, budgeting for unexpected home repairs and buying an affordable house. There are some areas in which players can make money. Can players buy run down houses and 'flip' them or buy multiple houses and rent them to other players?

Entrepreneurship: Can be considered for adding this to both after and before college career option. If they choose an entrepreneurship, things that can be focused on include marketing, sales, products, company name and logo, hiring, firing, bank loans, and venture capitalists.

Life Crisis: Things that can be considered for future work are medical costs, death in family, stock market crash, housing market crash, lost job, and child issues.

Retirement: Currently players have a $401 \mathrm{~K}$ in the game. For future work, budget, pay off loans vs. investing and making minimum payments, pension plan, stocks, bonds with insurance for each of the options can be considered.

Each of these stages provides a variety of quests related to decisions and planning that may need to be considered. Looking even more long term, programmers may want to consider each of these stages an individual island with various quests that need to be mastered before traveling to the next. This will involve different activities:

- It will create more segmented areas of concentration which allow for shorter more focused lesson plans,

- An ability to create a graduation process, similar to many video games currently on the internet, creates motivation to move on and receive more benefits

- $\quad$ An ability to segment out real world incentives and additional educational resources related to particular subject matter

- An ability to make each decision point more enriching and comprehensive which will ultimately enhance the learning process, but more importantly modify the players' behavior in the long term.

\section{SUMMARY}

The Financial Literacy Game project is an attempt to explore what may work in the next era of Financial Literacy education. It implements the latest technology for training and information dissemination. The project team 
has successfully designed, implemented, and validated the educational effectiveness of the game. Plans are underway for expansion of the material presented to incorporate other components of financial literacy education.

\section{ACKNOWLEDGEMENTS}

Filene Research Institute and Members United Corporate Federal Credit Union sponsored this project.

\section{AUTHOR INFORMATION}

Dr. Chang Liu, Associate Professor of Computer Science at Ohio University, specializes in software engineering and immersive technologies. Chang obtained his doctoral degree in Information \& Computer Science from the University of California at Irvine in 2002 and founded the VITAL Lab at Ohio University. He published over thirty refereed papers and won over twenty grants totaling over \$5M dollars. NSF, DARPA, the Department of Labor, U.S. EPA, Smithsonian Institution, and Ohio Learning Network funded his projects. Chang won the 2009 Marvin E. and Ann D. White Research Award and the 2007 Advanced Technology Summit Award for Leadership.

Dr. Teresa Franklin, Professor of Instructional Technology at Ohio University, specializes in instructional design and the development of e-learning content within virtual environments and online delivery systems. Dr. Franklin is co-author of Teaching Science for All Children which is presently in its 5th edition. She has numerous publications and presentations as well as invited international and national keynotes on the Games in the Middle School Science Classroom, Mobile Learning and New Learning Environments in Education. Dr. Franklin has secured over 11 million dollars in grants and received the Patton College of Education Research Award for her research on the implementation of digital science games in the middle school classrooms of Appalachian Ohio.

Dr. Roger Shelor is Fox Professor of Business and Professor of Finance at Ohio University, and serves a director of Community Savings. His doctorate is from The University of Kentucky. He received his MBA from Auburn University and BA from Virginia Tech University. Previously he was the Balsley-Whitmore Endowed Professor in Business at Louisiana Tech University and was on faculty at Eastern Kentucky University. He served as a consultant in the areas of Corporate Financial Management and Information Management, and as an expert witness in the areas of Finance, Economics, Statistics and Quantitative Analysis. He has published in business journals in the areas of Finance, Insurance, Real Estate, Information Systems, Business Education and Management.

Sertac Ozercan is a doctoral student in Computer Science at Russ College of Engineering at Ohio University in Athens, OH. He received his Master's degree in Computer Science through the Russ College of Engineering at Ohio University in 2010. Among his research interests are human-computer interaction, computer graphics, and game development.

Jarrod Reuter is a Master's student in Computer Science in the Russ College of Engineering and Technology at Ohio University. Jarrod's research focuses on Human-Computer Interaction in 3D Software Applications within 3D Virtual Worlds and the use of those applications to enhance education.

En Ye is a Ph.D. candidate of the School of Electrical Engineering and Computer Science in the Russ College of Engineering and Technology at Ohio University. En's research focuses on using 3-D virtualization created with game engines like Unity3D and online virtual worlds like Second Life to enhance collaboration in software development. En also developed 3D online games in Second Life to enrich education.

Scott Moriarty is a co-founder and CEO of Thwakk, Inc, and has over a decade of financial services and executive management experience. In his corporate career, Scott concentrated on leveraging technology to enhance the customer's user experience. His ability to combine technology and user perspective led to a variety of innovative solutions to enhance business development. As a member of Filene i3, Scott spearheaded the development of financial education through interactive, multi-player 3-D game design, which has captured the interest of the market. The project is highlighted in several credit union publications and commercially available through Thwakk. 


\section{REFERENCES}

1. Adams, D. Wireless Laptops in the Classroom (and the Sesame Street Syndrome). Communications of the ACM (Sep 2006), Vol. 49 Issue 9, 25-27.

2. Allen, E., Seaman, C. Making the Grade: Online Education in the United States, 2006, Research Report (2006), Needham: The Sloane Consortium.

3. American Medical Association. (n.d.). Medical Student Debt, Retrieved from http://www.amaassn.org/ama/pub/about-ama/our-people/member-groups-sections/medical-student-section/advocacypolicy/medical-student-debt.shtml.

4. Board of Governors of the Federal Reserve System. (February 24, 2009). Monetary Policy Report to the Congress - Part 2: Recent Financial and Economic Developments, Retrieved from http://www.federalreserve.gov/monetarypolicy/mpr 20090224 part2.htm.

5. Boshara, R. Poverty Is More Than a Matter of Income, The New York Times, September 22, 2002. Retrieved from http://www.nytimes.com/2002/09/29/opinion/poverty-is-more-than-a-matter-ofincome.html

6. Capital One. (July 21, 2009). Capital One's Annual Survey Finds Back-to-School Shopping Will Be Impacted by Economy, Retrieved from http://phx.corporate-ir.net/phoenix.zhtml?c=70667\&p=irolnewsArticle\&ID=1177193\&highlight.

7. Castronova E. Synthetic Worlds: The Business and Culture of Online Games. University Of Chicago Press (2005).

8. Dugas, C. Graduates saddled with debt, student loans can't easily turn to bankruptcy, USA TODAY. Retrieved from http://www.usatoday.com/money/perfi/2009-05-12-studentloans13_N.htm.

9. $\quad$ Fang Y., Siemer J., Zhong Y., Ye E., Liu C., Chang T. J. Virtual P3 Game: Play, Participation, and Protection for Environmental Education, ORBCRE '08: Ohio River Basin Consortium for Research and Education Scientific Symposium (October 2008).

10. Johnson, R., Middleton, J. Accounting for Second Life, Journal of Accountancy (Jun 2008), Vol. 205 Issue 6, 54-58.

11. Jump\$tart Coalition. Making the Case for Financial Literacy (2007). Retrieved from http://www.jumpstart.org/upload/Making\%20the\%20Case\%202007.doc.

12. Kantrowitz, M. Student Loans, FinAid Page (2010). Retrieved from http://www.finaid.org/loans/.

13. Kemp J., Livingstone D., Putting a second life metaverse skin on learning management systems, SLCC '06: Proceedings of the Second Life Education Workshop at Second Life Community Covention (2006), 1318.K

14. Palmer, K. Financial Literacy Crisis, USNews (April 2, 2008). Retrieved from http://www.usnews.com/articles/business/your-money/2008/04/02/financial-literacy-101.html.

15. RealtyTrac Inc. (n.d.). December 2008 U.S. Foreclosure Market Report, Retrieved from http://www.realtytrac.com/ContentManagement/pressrelease.aspx?ChannelID=9\&ItemID=5807\&accnt=64 $\underline{847}$.

16. Rymaszewski M., Au W., Wallace M., Winters C., Ondrejka C., Batstone-Cunningham B., and S. L. residents from around the world, Second Life the office guide. Wiley Press (2007).

17. Stone G. Financial Literacy, LOMA, June, 2004. Retrieved from http://www.loma.org/res-06-04literacy.asp.

18. The New America Foundation. (n.d.). Asset Building Program, Retrieved from http://www.newamerica.net/programs/asset building.

19. Visa. (August 9, 2005). Visa USA 2005 National Back to School Survey, Retrieved from http://www.newamerica.net/programs/asset building.

20. Wagner, C. Learning Experience with Virtual Worlds Journal of Information Systems Education (Fall 2008), Vol. 19 Issue 3, 263-266.

21. Wagner, J, Virtual World Population: 50 million by 2011, The GigaOM Network (May 20, 2007). Retrieved from http://gigaom.com/2007/05/20/virtual-world-population-50-million-by-2011.

22. Wood, N., Solomon, M., Allan, D. Welcome To The Matrix: E-Learning Gets A Second Life Marketing Education Review (Summer 2008), Vol. 18 Issue 2, 47-53. 
23. Ye E., Fang Y., Liu C., Chang T. J., Dinh H. Q. Appalachian Tycoon: an Environmental Education Game in Second Life, In SLCC '07: the 2007 Second Life Community Convention (Education Track) (Chicago, August 2007).

24. Ye E., Liu C., Polack-Wahl J. A. Enhancing software engineering education using teaching aids in 3-d online virtual worlds, FIE '07: Proceedings of the 2007 Frontiers in Education Conference (October 2007)

i $\quad$ http://www.sloodle.org

ii P3 (People, Prosperity, and the Planet) is EPA's explanation of P3, while P3 (Play, Participation, and Protection) is our explanation of P3.

iii http://opensimulator.org/wiki/Main_Page 